\title{
Survival and the Law: Human Life as the Presupposition of Practical Agency
}

\section{Maestri $\mathrm{E}^{*}$ \\ Department of Law, University of Ferrara, Italy}

*Corresponding author: Enrico Maestri, Associate Professor of Legal Philosophy, Department of Law, University of Ferrara, Corso Ercole I D'este 37, Ferrara, Italy, Tel: +393394270495; Email: enrico.maestri@unife.it

\section{Conceptual Paper}

Volume 2 Issue 3

Received Date: August 07, 2019

Published Date: August 23, 2019

DOI: $10.23880 /$ phij- 16000123

\section{Abstract}

The aim of this essay is to demonstrate that human life, biologically understood what I call the human bios embodies a moral criterion, a reason for action, having a minimum natural content. This criterion is based on the end-value of survival, that is, the need to live biologically and ensure the continuation of the human species. The argument that I put forward implies a rediscovery of the exceptional legal value of survival: a non-instrumental value, related to the forms of living that human beings decide to put into practice. In agreement with Hart, law is practicable if and only if a minimum content of natural law is respected: law is concerned with social arrangements, not with suicide club; no law is given that is, no legal order, relations or intersubjectivity when the rules are designed to bring about death rather than the assurance of living.

Keywords: Biological facts; Human survival; Minimum natural law; Truisms; Positive laws

\section{Introduction}

The bio-philosophical debate on the nature and original identity of the subject of moral rights has been caused by the new possibilities of man intervening in life ${ }^{1}$ [1-4]. The concept of person, understood as a moral subject in the full sense, has taken on a fundamental position in bio-legal discussion, because in the past twenty years the exceptional progress achieved in the field of biotechnologies [5], on one hand, and increasingly refined resuscitation techniques, which have enabled an improved prognosis for many serious diseases, on the

\footnotetext{
${ }^{1}$ For some overviews, see Düwell, Rehmann-Sutter and Mieth (2008), Kaczor (2005), Beyleveld and Brownsword (2001) and Bourgeois (2003).
}

other hand, have literally revolutionised the traditional way of viewing the beginning of life, the diachronic continuity of the person and the end of life.

I shall not delve into the complex theme concerning the concept of person [6], but will rather limit myself to discussing some conceptual issues in reference to the biological criterion I am defending.

The biological argument holds that it is sufficient to identify the existence of a human being, thus a human life subjectified by a living organism belonging to the species Homo sapiens sapiens, in order to consider the necessary and sufficient condition for attributing full moral protection to him to be verified. 


\section{Philosophy International Journal}

No personalist transcendence [7] is needed to understand that human life is sacred; that the human bios enjoys an absolute moral primacy; that this does not imply a lack of respect for other living beings and that, as noted by Diamond [8], it is sufficient to be human to be morally important: "Someone may be deprived, for part or all of his life, of distinctiveless human capacities like reason. A human life without the exercise of those capacities is his human life" (p. 59).

The essential premise of this argument lies in maintaining a bio-philosophical position, based on the knowledge and a correct interpretation of biology and life science, as the field of application of bio-law.

Taking biological facts seriously in order to argue rationally is not an exercise of fundamentalism; in fact, biological objectivity is not a holistic truth: no form of despotism of truth derives from it, but it renders the grammar of the living non-disposable to cultural or conventional transformations (p. 27) [9].

One might object that relying on facts is objectively difficult, because it is difficult to establish what facts are relevant in a bio-legal question, because it is perhaps impossible to ascertain facts that may aspire to be relevant.

The perspective adopted by bioethical dualism $[10,11]$ hinges precisely on this objection. Psychological qualities, understood as criteria for the epistemic discrimination between person and life, between person and nature, turn their back on scientific data: the human genetic makeup does not suffice to make a person [12].

The biological argument, by contrast, emphasises that the respect for human life derives from empirical evidence, by virtue of which all living beings are programmed to live, from the instant when they become an expression of their individuality until their vital functions cease and their tissues deteriorate in an irreparable manner. This programme is decided neither by cultural choices, nor by a preordained cosmic purpose, but is rather drawn "from the lowly sphere of biological fact which man shares with other animals" (p. 191) [13]: the general natural wish for survival is a general norm and biological normality. What does this truism imply from a normative standpoint?

In my opinion, the absolute and inviolable biologically sacred rule do not kill derives from the biological argument, because the right to life is not established by man in conventionalist terms aut Caesar, aut Nihil but by life itself, which on its own phylogenetically institutes the right to life as a factual situation.

Here the adjective "factual" means material necessity and normative normality: there is no epistemological leap between facts and values, between bios and ethos; the need to live is a fact that at the same time prescribes how to live and therefore renders a human being tout court a moral being. As noted by Wittgenstein (§ 217) [14], "if I have exhausted the justifications I have reached bedrock, and my spade is turned. Then I am inclined to say: "This is simply what I". Biological life is the bedrock on which our spade is turned: life, therefore, is a source of values and value itself; it is a necessary and sufficient condition for affirming that moral status belongs to a human being as such.

I thus believe that the biological criterion can serve as a cognitive basis for the construction of practical statements, understood not as conventional rules, but as rules inspired by intrinsic needs deriving from the biological constitution of a human being. Bios is the dimension of being that welds facts and values. The fundamental need to live conditions the normative structure of moral statements on the subject of life and death. From this perspective, moral facts exist in a similar manner to natural facts, irrespective of human beliefs. In relation to the fundamental need to live, moral facts depend on us, but not on our present choices and cultural beliefs. Moral statements are thus amenable to verification on the basis of the theory of truth as correspondence: they are true in that they are the result of an internal connection between natural human facts and certain moral properties $[15,16]$.

Eric Olson (p. 18) calls this criterion the "biological approach to personal identity. A person, therefore, is a living being belonging to a biological class" [17].

Olson's biological criterion affirms that the condition of persistence of numerical personal identity over time is due to the merely biological persistence of the human organism. The human being is an entity that persists over time as a living human organism. In this perspective, the concept of psychological (or metaphysical) person is a redundant concept, that is, it is not essential for the purpose of solving the problem of identity. From a heuristic viewpoint, the concept of person is recoverable only if one wishes to denote thereby a person as a phase sortal, indicating, that is, an accidental property that human beings can enjoy in certain periods of their existence. In contrast to this monistic approach, those who [18] defend property dualism (unlike pure Cartesian 


\section{Philosophy International Journal}

dualism) put forth the argument that persons are undoubtedly bodies, but they exhibit psychological properties (which Strawson calls P-predicates) that cannot be reduced to the material-bodily properties (which Strawson calls M-predicates) characterising a living being [19].

According to Spaemann [20], a person is a living being; "the primary ends of the human agent as an animal organism are to sustain life" (p. 22). Life cannot be conceived as a quality of a being, but rather as the being of this: life is the being of the living. Persons are living beings. Their being is living, their identification is identified with that of a living organism.

\section{We are Neural Flesh}

The continual oscillation between rootedness in nature and freedom from nature, between a rigidly nomothetic nature and an openly hypothetic culture, inevitably led twentieth-century philosophy to the dead end of the opposition between animal and man. The semantic meaning of the concept of physis was determined in an antinomic manner vis-à-vis the characteristics of freedom and self-determination of the human being.

It is commonly affirmed that human predicates are the fruit of biological vacuity, not of biological quality. Man is depicted is an incomplete being, which exonerates him from his shortcomings through an extra-biological dimension, along a path that starts off from his deficiency to explain the cultural outcome. Underlying this philosophical paradigm, developed by the negative anthropology of Gehlen, Scheler and Plessner, is the idea that a human being is a free subject, open to the good in itself, not limited to interest-wellbeing; a human being, moreover, has a world that is not anchored to the limits of preservation of himself and his species. In contrast, a nonhuman animal lives passively in an environment that is already given, from a phylogenetic viewpoint: it is confined within the limits of a purpose already determined by nature. Man ranks highest in terms of degree of subjectivity (theory of human excellence) because, as a biologically imperfect being, he is not bound by the logic of species self-preservation.

One could argue, therefore, that man is a biological being, belonging to the species Homo sapiens sapiens, and that, at the same time, he is a person, coextensive with himself, who frees himself from the species: as noted by Finnis [21] man transcends the boundaries of species because he is a person.
I uphold a view that develops along a different line of reasoning. It is a line which lends centrality to bios and sees bios, analysed in purely biological terms, as the root of morality and practical normativity. The biological component of a human being completely structures his subjectivity. Subjectivity is not an extravagant metaphysical hypothesis; it is founded upon psychological states that have a neurobiological origin. A human being possesses aptitudes and qualities: awareness, introspection, self-knowledge, mental imagery, empathy, abstract thought, and moral conscience. But all this has nothing to do with a perspective irreducible to a biological one: it is a form of spiritual fanaticism to think that freedom and moral responsibility are solely the product of conditioning originating from a cultural context, i.e. from a metaphysical indeterminacy of the human being.

In agreement with Jonas [22], human freedom is such only within a system of biological constraints, because it cannot constitute an external, metaphysical, mysterious addition to the rest of the cognitive endowments of the human animal. Freedom-hypothesis is a biological mode of the human being, serving as a means of knowing how to survive. There is thus no actual opposition between necessity and freedom or between nature and culture. The fact that cultural intentionality plays a part in the design of the duration of a life cannot give rise to the illusion of removing the historical modality of that design from its biological roots. It would mean, in practical terms, denying that the fundamental behaviour is to exist, that the fundamental knowledge is knowing how to exist, since, for a living organism, the fundamental knowledge is knowing how to survive.

The systemic complexity of the human brain and its neurophysiological processes (particularly the role played by the neocortex, which enables abstract, symbolic thought, along with moral responsibility) have made possible the establishment, from a biological standpoint, of a mental model of reality. In order to survive, human beings have developed a neurological structure enabling them to relate to aspects of reality that are not yet present, "to extend its power of response by imagination far beyond the narrow limits of what has already hit it, and so grasp wholes and anticipate emergencies" (p. 141) [23].

In this respect, it is possible to argue [24] that bios underlies the whole emotive-cognitive dynamics of the human subject. The moral value of a human being derives from his physical flesh -veritable neural flesh, which, from the very first instant, exhibits a genome with a precise 


\section{Philosophy International Journal}

somatic individuality, one that is absolutely unique and exclusive. A human being is his body and, together with his organs, a psychosomatic unit, not a thing. The respect for human life derives from a biological fact whereby all living beings are programmed to live, from the moment when they become an expression of an individuality of their own.

According to Olson's biological approach, you and I are animals: members of the species Homo Sapiens, to be precise" (1999, p. 4). All human persons are animals, not in the sense that our body consists of an animal, but that it is precisely us. Human beings are identical to their bodies and persist as long as their bodies continue to exist. These biological dynamics emphasise the biological value of culture, as man constructs his profile through learning processes, that is, by structuring his neural flesh on the basis of ontogenetic openings to the outside.

\section{Minimum Content of Natural Law and Basic Needs}

The conception of human life intrinsically implies several fundamental notions, defined by Winch (p. 43) [25] as limiting notions; these inevitably limit the ethical space encompassing the concepts of good and evil, which can be accepted or rejected.

My theory holds that one of the limiting notions derives from this observation: the human good consists in living the type of life that is essentially suited to an organism endowed with human nature. On the basis of this simple, obvious biological fact, it can be further affirmed that the need to live is a biological value. Human life is the ultimate value, because it contains within itself a biological value that is superior to any other secondary or cultural derived value. The human bios is the fact/value inherent in all living beings; it prescribes something to them: the wish to live.

As was demonstrated by Hans Jonas in Organism and Freedom, life cannot be confused with the simple Cartesian res extensa, because it manifests, right from its simplest forms, an orientation toward self-maintenance and growth. Through metabolism, life asserts itself and maintains itself constant: it bears witness to itself, affirming itself in the attempt to confirm its own existence.

To support this line of reasoning, I shall bring forth the argument advanced by Herbert Hart one of the most important legal philosophers of the twentieth century which he designated with the expression "minimum content of natural law". I shall now focus on some implications produced by the notion of the minimum content of natural law (or Hart's argument) in relation to the theory I am putting forward here.

Hart details his theory of the "minimum content of natural law" in chapter 9 of his most important essay, The Concept of Law. Several years earlier, however - precisely in 1958 Hart had set forth a few reflections which were a prelude to what would become the core of his argument ${ }^{2}$ [26-30]. In his 1958 article, entitled "Positivism and the Separation between Law and Morals", in the part where he discusses the problem of the relationship between ideal law and existing law, Hart asks himself whether it is not reasonable to think that every legal system should take into account some essential situations. But what exactly is essential?

Hart's answer (1958) [31] is formulated in the following terms: "We have only to consider how the whole of our social, moral, and legal life, as we understand it now, depends on the contingent fact that though our bodies do change in shape, size, and other physical properties they do not do this so drastically nor with such quicksilver rapidity and irregularity that we cannot identify each other as the same persistent individual over considerable spans of time" (p. 622).

This - Hart affirms - is an obvious fact, but "on it at present rest huge structures of our thought and principles of action and social life" (ibidem). It is evident that Hart distances himself from the psychological philosophical theories of Lockean inspiration, which in those years outlined positions on the subject of personal identity: human beings, in Hart's view, are living bodies, they are material, biological bodies whose identity derives from their persistence over time, their biological continuity. Psychic and moral faculties and abilities, with which the world is built, are based on facts of a biological nature and depend on the biological constitution of the human organism.

Hart himself legitimises this interpretation when, immediately after the passage quoted above, he affirms: suppose that men were to become invulnerable to attack by each other, were clad perhaps like giant land crabs with an impenetrable carapace, and could extract the food they needed from the air by some internal chemical process. In such circumstances (the details of which can be left to science fiction) rules forbidding the free use of ${ }^{2}$ See more fully Drury (1981), Hund (1996), Rivaya (2001), Orrego
(2004) and Ricciardi (2007). 


\section{Philosophy International Journal}

violence and rules constituting the minimum form of property with its rights and duties sufficient to enable food to grow and be retained until eaten - would not have the necessary nonarbitrary status which they have for us, constituted as we are in a world like ours (p. 623).

This observation, too, brings out an obvious fact, but one that tends constantly to be underestimated: moral behaviours are a measure of beings made up of flesh, not silicon; the human animal is vulnerable, and if he were not there would be no need to worry about devising the best system of norms in order to enable him to live, survive and coexist with others.

Hart makes a further fundamental distinction. Contrary to what is claimed by the teleological theories of natural law, according to which man is a being devoted to achieving a natural, preordained end or the utmost moral development of the goodness within human nature, Hart believes that it is not reasonable to go beyond "this modest aim of survival" because, though it is "of course we must be careful not to exaggerate the differences among human beings, but it seems to me that above this minimum the purposes men have for living in society are too conflicting and varying to make possible much extension of the argument that some fuller overlap of legal rules and moral standards is 'necessary' in this sense" (ibidem).

In this passage Hart not only highlights the notion that there is no necessary conceptual connection between law and morals, but he also and above all and this is what interests us most here sets out the basic concept of his thesis of the minimum content of natural law, i.e. the concept, from an anthropological viewpoint, of the priority of life, based on the simple contingent fact of humans' wish to continue living. Accordingly, Hart (1961, p. 191) affirms that "the proper end of human activity is survival".

This simple idea lies at the basis of a very attenuated (in a teleological sense) version of natural law and represents the core of Hart's argument. Human survival is a good and is based on a contingent fact, namely, the wish of most men to continue living. Hart remarked the idea that "The actions which we speak of as those which are naturally good to do, are those which are required for survival" (ibidem). Hart considers that "from the lowly sphere of biological fact which man shares with other animals", we may draw "something entirely obvious: it is the tacit assumption that the proper end of human activity is survival, and this rests on the simple contingent fact that most men most of the time wish to continue in existence" (ibidem).

The biological fact of wishing to live in itself justifies a precise normative perspective, both because it orients human beings toward living, which does not imply a lack of freedom in their choices, and because it imposes, as a non-negotiable limit, respect for the goal of survival pursued by all other human beings. This respect derives neither from a principle of a teleological nature (the way to the end is already marked) nor from a principle of an axiological nature (human life is sacred), but stems rather from a pragmatic assumption, according to which, rebus sic stantibus, most men wish to live.

This obvious biological fact, which has extraordinary bio-legal implications in terms of the caution, prudence and respect it induces us to display toward human life, is considered by Hart to be a contingent fact, irrelevant from a teleological viewpoint, yet at the same time so important as to enable us to infer, without any need to rely on skyhooks, a special status of survival in relation to human conduct. The fact that men wish to live in biological terms, there being no need to construct thick teleological natural law theories that present a preordained, perfectionist conception of the human good, is neither a self-evident nor irrelevant consideration from a normative standpoint. The minimal objective of living one's life biologically (Hart's thin teleology is concerned only with this ${ }^{3}$ ) [32] derives from a biological fact, and it is simultaneously a normative fact because "is reflected in whole structures of our thought and language, in terms of which we describe the world and each other. We could not subtract the general wish to live and leave intact concepts like danger and safety, harm and benefit, need and function, disease and cure; for these are ways of simultaneously describing and appraising things by reference to the contribution they make to survival which is accepted as an aim" (p. 192). Within this narrowed realm, the thesis of the minimum natural law establishes a connection between law and morals.

I shall now focus on some of the most relevant issues that may be raised by Hart's reflections. Firstly, man is an animal and lives in a close relationship with other animals. Secondly, the priority of safeguarding ones owns life profoundly influences the organisation and functionalization of the structures of political power for this purpose. Thirdly, the concept of aim which Hart defines in terms that are minimal (thin), but sufficient to identify, in the need to live, a bridge between fact and

\footnotetext{
${ }^{3}$ On deflective nature of Hart's thesis, see Allan (2007).
} 


\section{Philosophy International Journal}

value: that particular end is already ingrained in the biological system of living beings. Fourthly, the concept of need and the concept of function, connected to the concept of value, enable us to consider this end in natural terms and living as a need that is intrinsic to the biological constitution of human beings. The faculties and capacities that make moral life possible are not independent of the biological constitution of human beings, but are rather closely connected to the objective value objective in a biological sense of human wellbeing and survival. Fifthly, the fundamental need to live is the source of some aspects, such as health, disease, treatment and cures, on the basis of which we consider our life: the need to live conditions the normative structure of our moral approaches to the themes of life and death and represents a good reason which makes the logical weight that Hume's Law may have on bioethical questions wholly irrelevant. The natural aim of living (i.e. life in and for itself) makes all the phenomena which contribute to ensuring man's attainment of this ultimate end something that can be described and assessed: life in itself incorporates general, basic preferences that guide moral action, without admitting any possibility of cultural forms of moral indifference.

Furthermore, survival is the necessary and implicit assumption underlying any discussion on how to organise social institutions: it is easy to see, if we reflect on some obvious truths concerning human beings and the world we live in, that there are some fundamental rules of conduct that every social arrangement must contain if it wishes to survive. As noted by Hart (1961), "such rules do in fact constitute a common element in the law and conventional morality of all societies which have progressed to the point where these are distinguished as different forms of social control. With them are found, both in law and morals, much that is peculiar to a particular society and much that may seem arbitrary or a mere matter of choice. Such universally recognized principles of conduct which have a basis in elementary truths concerning human beings, their natural environment, and aims, may be considered the minimum content of Natural Law, in contrast with the more grandiose and more challengeable constructions which have often been proffered under that name" (p. 193) ${ }^{4}$ [33].

In light of this particular observation, Hart's argument demonstrates that awareness of these facts about human nature should give us reason to accept a law, which

\footnotetext{
${ }^{4}$ According to another version of the minimum content of law, see GRIFFIN (2001).
}

satisfies the requirements imposed by the minimum content of natural law. Just as Jhering, in his book Der Zweck im Recht [Purpose in Law], he held that the purpose in law was to assure the conditions for the existence of society, Hart similarly saw the purpose of law as being that of assuring human survival, as a natural wish assumed to be shared by all human beings. Just as Hobbes deemed it essential to establish a rational connection between some characteristics of human nature and the content of legal systems, Hart believed it possible to characterise the minimum content of legal norms in relation to the "wish to live" of most human beings.

In contrast with Kelsen, who held that law could have any content whatsoever, Hart stresses that the truisms regarding human nature are based on lowly biological facts that "afford a reason why, given survival as an aim, law and morals should include a specific content" (p. 193) ${ }^{5}$ [34]. Hart lists five obvious truths (i.e. five natural necessities), which may be summed up as follows: 1 . Human beings are vulnerable; Hart observes that "were to lose their vulnerability to each other there would vanish one obvious reason for the most characteristic provision of law and morals: Thou shalt not kill" (pp. 194-195); 2. Despite the fact that a certain difference exists among humans in terms of physical strength and intellectual ability, there is nonetheless an approximate equality among them; Hart observes that even the strongest must sleep at times and, when asleep, loses temporarily his superiority (p. 195); 3. Regarding the argument of limited altruism, Hart observes that "men are not devils dominated by a wish to exterminate each other, and the demonstration that, given only the modest aim of survival, the basic rules of law and morals are necessities, must not be identified with the false view that men are predominantly selfish and have no disinterested interest in the survival and welfare of their fellows. But if men are not devils, neither are they angels; and the fact that they are a mean between these two extremes is something which makes a system of mutual forbearances both necessary and possible" (p. 196); 4. Human beings need natural resources in order to survive, but the earth's resources are not unlimited: this fact makes it necessary to control them and allocate them so as to avoid the abuse of goods and, therefore, to introduce some minimal system of property; 5 . Men's understanding, intelligence and strength of will are limited; this makes it necessary to establish an organised system such as to enable voluntary cooperation and assurance obedience to rules.

\footnotetext{
${ }^{5}$ Against Hart's thesis, see EPSTEIN (2005).
} 


\section{Philosophy International Journal}

This framework of expectations, demands and needs delineates the goods and the fundamental rights to be ensured $^{6}$ [35] and defines a limit for moral indifference that cannot be trespassed: the general goal of survival naturally obliges us not to be indifferent to one another. This minimal, but general circumstance, based on mutual obligations and virtues ${ }^{7}$ [36], represents, in my opinion, the common core of bioethical issues, since they regard questions of life and death, where the intersubjective dimension of the bioethical deliberative process is justified on the basis of a common aim: unconditional and absolute respect for one's own life and the life of others.

I would like to conclude my reflections on Hart's argument by drawing attention to two peculiar aspects. The first regards the similarity between Hart's argument and the Hobbesian model of natural law. The second regards the relationship between Hart's argument and the functional concept of virtue.

As regards the first aspect, according to the opinion which emerges from critical literature, the theory of the minimum content of natural law originates from Hart's adherence to the anthropological model of natural law proposed by Hobbes in Leviathan. Hart (p. 191) [13] himself admits this direct influence when he affirms that Hobbes and Hume "have seen in the modest aim of survival the central indisputable element which gives empirical good sense to the terminology of Natural Law".

The Hobbesian influence on Harts argument manifests itself in the connection between the principle of selfpreservation upon which the fundamental, essential right to life is based and the structure of political power, which is entrusted with the task of assuring the absolute good of peace. In Hobbes view, the foundation and raison detre of the principle of obedience to the sovereign's law lie not in the intrinsic value of his commands as such, but rather in the value of self-preservation of the life of each citizensubject. For Hart as well, the preservation of human life, understood as a good to be defended within the framework of social arrangements, obliges the social and legal orders to consider respect for the life of every human being as an institutional practice and purpose.

\footnotetext{
${ }^{6}$ In this way, Hart's truisms could justify the argument that only basic needs can directly ground human rights; see MILLER (2007).

${ }^{7}$ Ad noted by Mitchell (2000, p. 45): "The obligations and virtues occur in the list are there because their recognition and sufficient practice is held to be a necessary condition of any tolerable human existence. They are not logically necessary, as Kant thought, but, to use Strawson's phrase, humanly necessary".
}

The another aspect of Hart's argument regards the functional concept of virtue, a notion the Oxonian philosopher insists on from a semantic viewpoint in order to indicate the nature of survival. Whilst the Hobbesian part of Hart's argument focuses attention on the relationship between survival and power, this aspect highlights a Neo-Thomist part of Hart's argument (probably influenced by the anti-Cartesian turn of Wittgenstein and his followers). The theme of survival is connected to a concept of biological functionality, based on which it is possible to affirm that the specific difference that may be attributed to all living beings, be they human beings or non-human animals, is not so much the capacity to think, which can be a characteristic trait of an animal as a bearer of a specific life-form (p. 76) [37], but rather, more generally, the capacity to live. All living beings tend to perform a set of natural functions which are geared toward some good or tend to identify goodness in relation to their life form or the natural species they belong to.

If, therefore, the "good" for living beings depends on what is necessary for "functioning well" in relation to the species they belong to, the natural wish to survive reflects the primary, minimal natural need that all animals seek naturally to fulfil.

It is often affirmed that man, unlike non-human animals, possesses an excellence of mind that man himself pursues to the highest degree of perfection. However, a human being uses practical reasoning or rational thought not because it is outside Nature but because it is part of what makes our species what it is. In this regard, our needs, our expectations and others' reactions lend form to a system of "universal values. It is indeed arguable that a human society in which these values are not recognised at all in its morality is neither an empirical nor a logical possibility, and that even if it were, such a society could be of no practical value for human beings" (p. 70) [38].

In Hart's view [13] "it is latent in our identification of certain things as human needs which it is good to satisfy and of certain things done to or suffered by human beings as harm or injury. Thus, though it is true that some men may refuse to eat or rest because they wish to die, we think of eating and resting as something more than things which men regularly do or just happen to desire. Food and rest are human needs, even if some refuse them when they are needed. Hence we say not only that it is natural for all men to eat and sleep, but that all men ought to eat and rest sometimes, or that it is naturally good to do these things. [...]<>The same outlook is present in our conception of the functions of bodily organs and the line 
we draw between these and mere causal properties" (pp. 190-191).

\section{Human Life as Presupposition of Positive Laws}

Hart has thus perceived that the biological function is not a mere causal property, but is rather a necessary form on which a good depends: here, exactly, lies the difference between a Cartesian model and a biological model of explaining living beings.

Hart keeps his gaze turned downward, towards lowly biological facts: the actions which we speak of as those which are naturally good to do, are those which are required for survival; the notions of a human need, of harm, and of the function of bodily organs or changes rests on the same simple fact (p. 191). This downward gaze makes human animals aware of and responsible for other living creatures; directed towards human beings to remember that dignity is the manifestation of human life as represented by the human body.

It may be plausibly maintained, moreover, that Harts argument puts out of the question the prohibitions of Hume's Law: "to raise this or any other question concerning how men should live together, we must assume that their aim, generally speaking, is to live" (p. 192). The reasoning adopted by Hart in order to establish the basis of the minimum content of natural law is a clear example of how to found moral values through the logic of presuppositions. In practical terms, if " $\mathrm{X}$ is a presupposition", we can say that the sentence " $\mathrm{X}$ is a value" is irrefutable either because refuting it would be pragmatically contradictory or because the sentence needs no justification. However, the ultimate foundation, in both cases, is the same and lies in the fact, detectable in a pragmatic dimension, that that presupposition is present and attested to in each one of its justifications as in each one of its negations. Presuppositions are conditions that are not instrumental, but constitutive, that is, categorical and prejudicial conditions of moral discourse. For example, the negation of an ethical principle such as the respect for life, as a negation of the presuppositions informing the moral discourse, produces an irrational position, given that, if an ethical principle has presuppositions, the latter also become essential conditions of its antithesis. In the case of Hart's argument, life becomes a general value not because it is sacred $a$ priori, but to the extent that the natural wish for survival constitutes the presupposition of every ethical or juridical discussion. One cannot negate life, because the very act of negating it becomes a confirmation if it has been assumed as the presupposition of questions related to the manner in which one must live. The presupposition of survival justifies, moreover, an internal or minimal teleological approach to the problem of values, in that it may be affirmed to denote a quality shared by all human beings as such. Ethical assessments imply volition, aims and preferences on the part of whoever is formulating them; it is evident that if an aim is recognised by all those making a judgement within the intersubjective structure of normative discourse, the situation produced by the common end produces a universal value which may not be refuted by any of those judging. The existence of essential needs becomes a necessary and sufficient condition of ethical values: something is a moral value if, and only if, it corresponds to common aims. In this respect, for Hart, the wish to survive is not only a presupposition of moral discourse, but also a general value, that is, shared by all individuals as human beings.

Thus there is a logical precedence of corporeality with respect to every questionable object of having: the wish to live, the wish to be, the wish to realise oneself through and with one's body are a basic presupposition, not a possible subject of bioethical discussion. Bios represents the possibility of being and simultaneously of becoming in the many different modes of being: it is the precondition, the natural archetype, without which the multiple transformations that free will exercises in our being could not take place.

Reflecting on life is possible if we recognise that the "fact of life", in both its complexity and ultimate simplicity, is the precondition, the biological determinant of human action.

In Hart's view, life has a fundamental value, because it makes us aware of others' needs and expectations. It is a necessary and sufficient precondition for enabling human existence, which, in turn, is the ultimate justification underlying all ethical discourse.

The starting point from which we may derive obvious truths about human beings, human vulnerability first and foremost - is the tacit assumption of survival as a shared, general end.

In this respect, we might attempt to give an answer to the ultimate question around which bio-law revolves: how should we address life and death issues?

Well, Hart [13] affirms that there are considerations which show "acceptance of survival as an aim to be necessary, in a sense more directly relevant to the 


\section{Philosophy International Journal}

discussion of human law and morals, We are committed to it as something presupposed by the terms of the discussion" (p. 192); if, therefore, we ask ourselves the question how we should live, this presupposes an acceptance of living as an essential need. According to Hart (p. 192), such an aim acquires a general value if in the question "how should we live? it is implicit that "our concern is with social arrangements for continued existence, not with those of a suicide club".

\section{References}

1. Düwell M, Rehmann-Sutter C, Mieth D (2008) The Contingent Nature of Life: Bioethics and Limits of Human Existence. Dordrecht: Springer.

2. Kaczor C (2005) The Edge of Life: Human Dignity and Contemporary Bioethics. Dordrecht: Springer.

3. Beyleveld D, Brownsword R (2001) Human Dignity in Bioethics and Biolaw. Oxford: Oxford University Press.

4. Bourgeois W (2003) Persons. What Philosophers Say about You. Waterloo (CA): Wilfrid Laurier University Press.

5. DeGrazia D (2005) Human Identity and Bioethics. Cambridge: Cambridge University Press.

6. Walters JW (1997) What is a Person? An Ethical Exploration. Chicago: University of Illinois Press.

7. Grisez G, Boyle J (1979) Life and Death with liberty and justice. A contribution to the euthanasia debate. Notre Dame and London: University of Notre Dame Press.

8. Diamond C (1991) The Importance of Being Human. In: Cockburn D (Eds.), Human Beings, Cambridge: Cambridge University Press, pp: 35-62.

9. Habermas J (2003) The Future of Human Nature. Cambridge: Polity Press.

10. Engelhardt H (1996) The Foundations of Bioethics. New York: Oxford University Press.

11. Lockwood M (1985) Moral Dilemmas in Modern Medicine. Oxford: Oxford University Press.

12. Splitter LJ (2015) Identity and Personhood. Confusion and Classification across Disciplines. New York: Springer.
13. Hart HLA (1961) The Concept of Law. Oxford: Clarendon Press.

14. Wittgenstein L (1958) Philosophical Investigations. Oxford: Basil Blackwell.

15. Lee $P$ (2004) The Pro-Life Argument From Substantial Identity: A Defence. Bioethics 18(3): 249263.

16. Lee P, George R (2008) Body-self dualism in contemporary ethics and politics. Cambridge: Cambridge University Press.

17. Olson ET (1997) The human animal: personal identity without psychology. Oxford: Oxford University Press.

18. Rudder Baker L (2000) Persons and Bodies. A Constitution View. Cambridge: Cambridge University Press.

19. Strawson PF (1959) Individuals. An Essay in Descriptive Metaphysics. London: Methuen.

20. Spaemann R (2006) Persons. The Difference between 'Someone' and 'Something. Oxford: Oxford Universiy Press.

21. Finnis J (2011) Intention and Identity. Collected Essays: Volume II. Oxford: Oxford University Press.

22. Jonas H (1966) The Phenomenon of Life. Toward a Philosophical Biology. New York: Harper \& Row.

23. Midgley M (1998) Animals and Why They Matter. Athiens: The University of Georgia Press.

24. Esposito R (2008) Bios. Biopolitics and Philosophy. Minneapolis: University of Minnesota Press.

25. Winch $P$ (1972) Understanding a primitive society, in Ethics and Action (London: Routledge), pp: 8-49.

26. Drury SB (1981) H.L.A. Hart's Minimum Content Theory of Natural Law. Political Theory 4: 533-541.

27. Hund J (1996) HLA Hart's Contribution to Legal Anthropology. Journal for the Theory of Social Behaviour26: 275-292.

28. Rivaya B (2001) On theories of the minimum content of natural law Constructions or reconstructions. Rechtstheorie 32: 65-86. 
29. Orrego C (2004) H.L.A. Hart's Understanding of Classical Natural Law Theory. Oxford Journal of Legal Studies 24(2): 287-302.

30. Ricciardi M (2007) Diritto naturale minimo. In: Coliva A (Eds.), Filosofia analitica. Temi e problemi, (Roma: Carocci), pp: 379-401.

31. Hart HLA (1958) Positivism and the Separation of Law and Morals. Harvard Law Review 4: 593-629.

32. Allan J (2007) Is You Is or Is You Ain't Hart's Baby? Epsteins Minimum Content of Natural Law. Ratio Juris 2: 213-229.

33. Griffin J (2001) First Steps in an Account of Human Rights. European Journal of Philosophy 3: 306-327.
34. Epstein RA (2005) The Not So Minimum Content of Natural Law. Oxford Journal of Legal Studies 25(2): 219-255.

35. Miller D (2007) Diritti umani, bisogni fondamentali e scarsità. Ragion pratica 29: 433-447.

36. Mitchell B (2000) Morality: Religious \& Secular. New York: Oxford University Press.

37. Thompson M (2008) Life and Action. Elementary Structures of Practice and Practical Thought, Cambridge: Harvard University Press.

38. Hart HLA (1968) Law, Liberty and Morality. Oxford: Oxford University Press. 